\title{
Bombeamento de água utilizando sistemas fotovoltaicos
}

O bombeamento de água é uma das atividades mais difundidas em relação à utilização da energia solar fotovoltaica. Uma característica muito favorável ao uso dessa tecnologia refere-se ao casamento perfeito entre a fonte energética, a radiação solar e a necessidade de água. 0 sistema de bombeamento de água fotovoltaico é semelhante aos sistemas convencionais, com a diferença básica que o acionamento do motor da bomba é feito por um conjunto de módulos fotovoltaicos. O objetivo deste artigo foi realizar uma revisão de literatura sobre o bombeamento de água utilizando sistemas fotovoltaicos e comparar as vantagens e desvantagens do respectivo sistema. A metodologia utilizada pautou em uma revisão de literatura onde a amostra foi composta de artigos, monografia, normas, periódicos publicados em revistas nacionais com data de publicação compreendida entre os últimos oito anos. Nos resultados da pesquisa foram selecionados 17 (dezessete) publicações, sendo que ao final concluiu-se que que as vantagens de utilização desse sistema, as mesmas pautam-se em: pouca manutenção; possui sistemas modulares que podem ser aumentados ou diminuídos, conforme a necessidade de bombeamento; não utiliza combustível fóssil; é um sistema silencioso e confiável; possui uma longa vida útil; não polui; é um sistema confiável; possui operação autônoma; tem baixo custo de operação e evita gastos permanentes (gastos com aquisição de combustíveis, por exemplo). Já as desvantagens, as mesmas pautam-se em: exige um alto investimento inicial; é uma tecnologia ainda pouco utilizada; depende do recurso solar.

Palavras-chave: Bombeamento de Água; Energia Solar; Sistema Fotovoltaico.

\section{Pumping water using photovoltaic systems}

Pumping water is one of the most widespread activities in relation to the use of photovoltaic solar energy. A very favorable feature to the use of this technology refers to the perfect marriage between the energy source, solar radiation and the need for water. The photovoltaic water pumping system is similar to conventiona systems, with the basic difference that the pump motor is driven by a set of photovoltaic modules. The purpose of this article was to conduct a literature review on water pumping using photovoltaic systems and to compare the advantages and disadvantages of the respective system. The methodology used was based on a literature review where the sample consisted of articles, monograph, norms, journals published in national magazines with publication date between the last eight years. In the research results, 17 (seventeen) publications were selected, and in the end it was concluded that the advantages of using this system, are based on: little maintenance; it has modular systems that can be increased or decreased, depending on the need for pumping; does not use fossil fuel; it is a quiet and reliable system; has a long service life; does not polute; it is a reliable system; has autonomous operation; it has low operating costs and avoids permanent expenses (expenses with fuel purchases, for example). The disadvantages, on the other hand, are based on: it requires a high initial investment; it is a technology still little used; depends on the solar resource.

Keywords: Water Pumping; Solar energy; Photovoltaic system.

Topic: Engenharia Civil

Reviewed anonymously in the process of blind peer.
Received: $17 / 12 / 2020$

Approved: 10/03/2021

Rafael Frank Alves Pereira

rafaelfrankap@hotmail.com

\section{Referencing this:}

PEREIRA, R. F. A.. Bombeamento de água utilizando sistemas fotovoltaicos. Engineering Sciences, v.9, n.1, p.85-91, 2021. DOI: http://doi.org/10.6008/CBPC2318-3055.2021.001.0009 


\section{INTRODUÇÃO}

A energia solar sempre foi uma fonte de energia importante. As plantas transformam a energia solar em alimento usando a fotossíntese. Os animais, incluindo o ser humano, ingerem as plantas. Dessa maneira, a energia solar tem alimentado o planeta desde o início. Quase toda a energia utilizada pelo ser humano pode ter sua origem reconstituída até o sol. O carvão, o petróleo, a madeira e até mesmo a eletricidade são fontes energéticas produzidas pela energia do sol (BALFOUR et al., 2019).

O objetivo de aproveitar a energia solar sempre foi criar uma fonte de energia que não desperdiça recursos. O mundo dos negócios levou muito tempo para reconhecer que existem muitos benefícios e oportunidades em investir na tecnologia de energia solar. Hoje, a energia fotovoltaica (FV) está chamando a atenção dos fornecedores de energia. Há necessidade de técnicos capacitados em projeto e instalação, além de engenheiros que possam fornecer sistemas FV de alto desempenho, confiáveis e com uma boa relação custo-benefício (URBANETZ JUNIOR et al., 2014).

Propõe-se aqui desenvolver uma pesquisa voltada para o estudo de bombeamento de água utilizando sistemas fotovoltaicos, uma vez que a energia solar é algo promissor que pode ser utilizada na geração de eletricidade através de painéis fotovoltaicos para iluminação e bombeamento de água. Alvarenga (2019) destaca que os mecanismos de condicionamento de potência, como inversor, controlador, seguido do ponto de máxima potência; grupo motobomba; sistema de armazenamento (opcional) e sistema de distribuição são módulos FV que constituem um sistema de bombeamento.

A geração autônoma, diferentemente dos sistemas domiciliares, não utiliza baterias eletrolíticas para armazenar energia elétrica produzida nos horários de maior insolação para sua posterior utilização, a exceção é feita, contudo, nos casos em que a bomba é uma carga maior do que um sistema FV autônomo. No sistema de bombeamento $\mathrm{FV}$, nos períodos em que ocorre maior insolação, a água é bombeada e armazenada em reservatórios que vão acumulando a água bombeada para posterior utilização. Esses reservatórios são dimensionados para prestar determinado serviço, em certos números de dias de autonomia (DAL BEM et al., 2016).

Quanto à classificação dos sistemas de bombeamento, Vicentin et al. (2016) os dividem em dois grupos: sistema direto e sistema indireto. A constituição dos dois tipos difere apenas no uso de baterias pelo sistema indireto, contudo, com vistas ao menor custo total do sistema, o sistema direto é mais usual, reservando-se a aplicação indireta apenas quando é necessário realizar o bombeamento em horário sem insolação. Além disso, o sistema direto pode usar ou não um conversor de potência.

Para cumprir sua função, por meio do trabalho conjunto de tubulações, acessórios, bomba(s) e motor(es), o sistema de bombeamento converte diferentes formas de energia (seja elétrica, cinética, da queima de combustíveis, entre outras) em energia mecânica e a transfere ao fluido de trabalho para que este possa ser transportado de um reservatório inferior, ou de uma captação, para um reservatório superior ou ponto de consumo (JIMÉNEZ, 2017).

O tamanho da estação elevatória varia de acordo com o porte do sistema a ser atendido, 
características da área, regime de trabalho, entre outros fatores; porém, um sistema de bombeamento padrão possui três partes principais, que serão detalhadas a continuação: Tubulação (sucção e recalque); Conjunto elevatório (motor e bomba); e, Poço (úmido e seco) (CARVALHO, 2016).

O dimensionamento e escolha do motor e da bomba dependem um do outro, pois para cada aplicação existirá um conjunto motobomba que tenha um melhor desempenho de acordo com as condições de trabalho. Assim, é necessário conhecer os diferentes equipamentos disponíveis e entender que aplicação explora melhor suas características para optar sempre pela melhor opção em termos de eficiência e baixo custo (PINHO et al., 2014).

Com relação ao tipo de fluxo que induzem, as bombas podem ser divididas em duas categorias: as volumétricas, ou de deslocamento positivo, e as turbobombas, também chamadas de cinéticas, ou ainda de bombas de fluxo (ALVARENGA et al., 2014).

As bombas volumétricas possuem uma ou mais câmaras sobre a qual algum elemento móvel atua aumentando a pressão e provocando o movimento, que após uma rotação de seu eixo, desloca um volume fixo de produto, independentemente das condições de pressão na saída. Estas bombas caracterizam-se por trabalhar com baixas vazões e altas pressões e podem ser utilizadas com fluidos mais espessos, onde o exemplo mais comum são as bombas de concreto (que equipam os caminhões betoneira das centrais de concreto) (ZILLI, 2018).

No caso das turbobombas, sua principal característica é a presença de um elemento girante dotado de pás chamado de rotor, movido por alguma fonte de potência através do seu eixo. A carcaça alberga ao conjunto, deixando em evidência o eixo, que transfere a potência de acionamento à sucção, por onde o fluido entra no conjunto, e à descarga, por onde ele sai. A parte da carcaça que contém o rotor se chama voluta, possui uma forma espiral que produz uma seção de escoamento crescente na periferia do rotor. O contínuo crescimento da seção de escoamento na voluta e bocal produz uma conversão de energia cinética em pressão. Estes dispositivos, em que ocorre a conversão de energia cinética em pressão, são chamados de difusores (FERNANDES, 2017).

Para bombeamento de água, as bombas centrífugas, mistas e axiais, são as mais utilizadas. Porém, para satisfazer as diversas aplicações, o rotor sofre certas mudanças, sendo classificados como rotores fechados, abertos e semiabertos. Rotores fechados são adequados ao bombeamento de líquidos limpos ou puros, preferencialmente, já que os dutos formados no seu interior podem ser facilmente obstruídos; enquanto que rotores abertos e semiabertos são ideais para bombear pastas, lamas e outros líquidos com partículas em suspensão, como esgotos sanitários (BOITRAGO et al., 2016).

Assim, o objetivo desta pesquisa pautou-se em realizar uma revisão de literatura sobre o bombeamento de água utilizando sistemas fotovoltaicos e comparar as vantagens e desvantagens do respectivo sistema.

\section{METODOLOGIA}

Trata-se de um estudo secundário, uma vez que estabeleceu conclusões a partir de estudos 
primários, que já foram publicados na literatura. Foi realizada uma revisão bibliográfica do tipo descritiva com abordagem qualitativa.

A pesquisa do tipo descritiva observa, registra e analisa fenômenos, sem manipulá-los. Procura descobrir a frequência, sua natureza, características e sua relação com outros fenômenos. A abordagem qualitativa se preocupa, com as ciências sociais, com um nível de realidade que não pode ser quantificado, apenas analisado e estudado (MINAYO, 2010).

Foi realizado um estudo retrospectivo, onde a amostra foi composta de artigos, monografia, normas, periódicos publicados em revistas nacionais com data de publicação compreendida entre os últimos oito anos, o que totalizou 16 (dezesseis) publicações. Os critérios de inclusão foram: ter publicação com data compreendida entre 2013 a 2020; ter como palavra-chave bombeamento de água ou fluídos; sistema fotovoltaico; energia solar.

Para melhor entendimento das literaturas selecionadas, a Figura 1 demonstra as mesmas conforme a seleção realizada no banco de dados e respectivo ano de publicação.

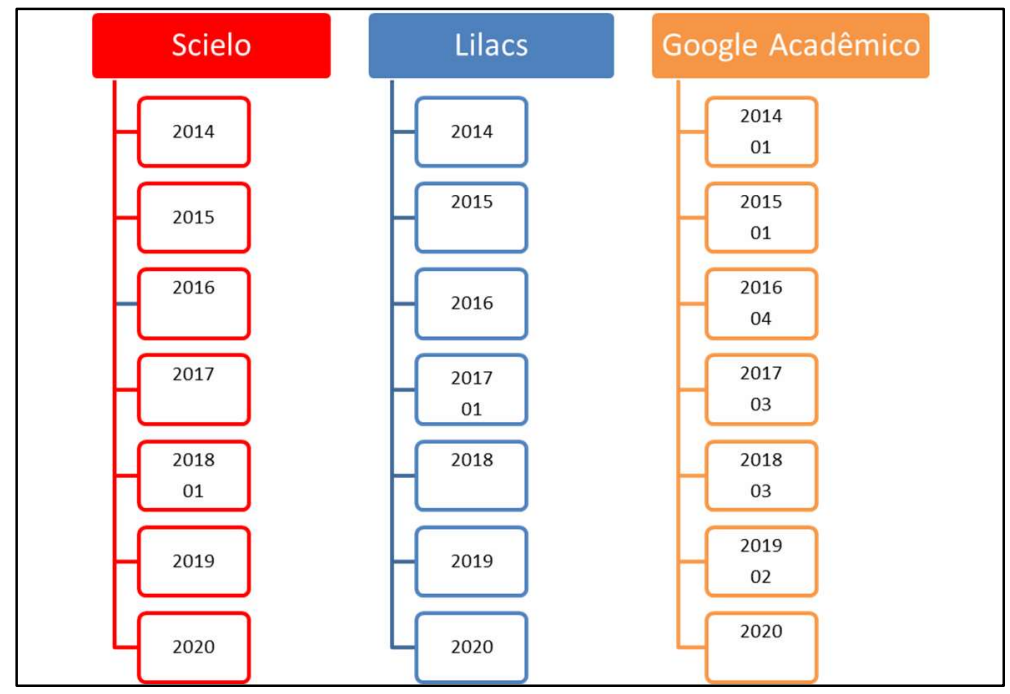

Figura 1: Fluxograma das literaturas selecionadas conforme a busca realizada no banco de dados e o ano de publicação do material.

\section{DISCUSSÃO TEÓRICA}

Os sistemas fotovoltaicos são compostos por painéis solares, inversor interativo e outros componentes que são utilizados para produzir energia através da captação dos raios solares. Os painéis ou placas solares contêm certa quantidade de células solares, unidade básica de geração da tecnologia, dentro da qual acontece a transformação da luz solar e energia. Esta fonte de energia pode ser aplicada ao consumo constante de água, seja pelo seu aquecimento ou mesmo bombeamento. A opção fotovoltaica é mais competitiva em localidades mais afastadas de grandes centros, podendo ser mais vantajoso que geradores à diesel em determinadas regiões (ZILLI, 2018).

O bombeamento de água por meio dos sistemas fotovoltaicos é uma opção que tem se mostrado bastante promissora, uma vez que é um recurso solar que ocorre em todo o mundo, sendo sua utilização uma solução mediante dimensionamento. Outro ponto é que o bombeamento de água utilizando sistemas 
fotovoltaicos evita gastos permanentes na aquisição e transporte de combustível, bem como a emissão de gases poluentes e de ruídos na geração. É uma tecnologia consolidada tecnicamente, de alta confiabilidade e com uma vida útil de gerador de mais de 25 anos (BOITRAGO et al., 2016).

Oliveira et al. (2018) colocam que, atualmente, existem diversas alternativas para realizar o bombeamento de água em situações onde não se tem acesso à rede elétrica, ou apresenta um deficiente fornecimento, tais como bombas manuais, bombas com motor a combustão interna, bombas movidas à energia eólica e bombas movidas à energia solar fotovoltaica, sendo que as bombas de sistema fotovoltaico (energia solar), tem se apresentado como a forma mais vantajosa, conforme demonstra o Quadro 1.

Quadro 1: Comparativo das vantagens e desvantagens entre alguns tipos de sistemas de bombeamento de água.

\begin{tabular}{|c|c|c|}
\hline TIPO DE BOMBA & VANTAGENS & DESVANTAGENS \\
\hline Manual & $\begin{array}{l}\text { Baixo custo; } \\
\text { Fácil manutenção; } \\
\text { Não necessita combustível. }\end{array}$ & $\begin{array}{l}\text { Manutenção frequente; } \\
\text { Baixo fluxo de água; } \\
\text { Demanda tempo e esforço físico. }\end{array}$ \\
\hline Solar Fotovoltaica & $\begin{array}{l}\text { Pouca manutenção; } \\
\text { Não necessita combustível; } \\
\text { Sistemas modulares; } \\
\text { Silencioso e confiável; } \\
\text { Vida útil longa; } \\
\text { Não poluente; } \\
\text { Evita gastos permanentes; } \\
\text { Baixo custo de operação; } \\
\text { Operação autônoma; } \\
\text { Alta confiabilidade. }\end{array}$ & $\begin{array}{l}\text { Investimento inicial alto; } \\
\text { Depende do recurso solar; } \\
\text { Tecnologia pouco difundida. }\end{array}$ \\
\hline Diesel & $\begin{array}{l}\text { Portátil; } \\
\text { Fácil instalação. }\end{array}$ & $\begin{array}{l}\text { Investimento inicial moderado; } \\
\text { Emissão de ruídos e gases poluentes; } \\
\text { Risco de contaminação do solo e da água subterrânea; } \\
\text { Vida útil curta; } \\
\text { Uso de combustível fóssil. }\end{array}$ \\
\hline Eólica & $\begin{array}{l}\text { Funciona com baixa velocidade do vento; } \\
\text { Vida útil longa. }\end{array}$ & $\begin{array}{l}\text { Dependência do recurso eólico; } \\
\text { Requer alta manutenção; } \\
\text { Baixa produtividade. }\end{array}$ \\
\hline
\end{tabular}

Fonte: Oliveira et al. (2018).

Segundo Zago (2017), atualmente existem, basicamente, três sistemas de bombeamento de água fotovoltaico, sendo os mesmos: 1) Sistemas de baixa potência (50 até $400 \mathrm{Wp}$ ): utilizam principalmente um motor em corrente contínua que aciona uma bomva de deslocamento positivo com diafragma. Entre o gerador fotovoltaico e o motor é instalado um conversor (corrente contínua/corrente contínua) para otimizar seu acoplamento. Como exemplo, existem os sistemas Solarjack SDS ou Shurflo 9300; 2) Sistemas de medida potência (de 400 a 1500Wp): são sistemas formados por duas configurações, sendo uma bomba centrífuga submersa multiestágios com motor assíncrono acionado por um inversor de frequência variável (sistemas Grundfos com condicionamento de potência tipo SA400 e SA1500) e outro formado por um motor de corrente contínua sem escovas (nesta faixa de potências podem ter um rendimento maior do que os motores trifásicos de indução convencionais e muito superior aos motores de indução monofásicos) operando uma bomba de deslocamento positivo helicoidal; 3) Sistemas que utilizam um conversor de frequência mais motobomba centrífuga multiestágios ou de deslocamento positivo (ambos de utilização industrial). Esses superam a máxima potência atingida pelos sistemas dedicados à tecnologia fotovoltaica (1600 Wp), tornando-se uma solução viável, eficiente e econômica. 
Para a implantação de um sistema de bombeamento de água utilizando sistemas fotovoltaicos é necessário realizar uma avaliação de desempenho do sistema a ser implantado, sendo que essa avaliação pode ser realizada por meio da utilização de um programa de simulação, no qual são considerados diversos parâmetros inerentes ao sistema, como a localização geográfica, radiação solar, padrão de consumo de água e aspectos hidrogeológicos (CARVALHO et al., 2018).

Carvalho (2016) descreve uma pesquisa que desenvolveu um programa de computador para simular o desempenho de um determinado sistema fotovoltaico de bombeamento de água doméstico. Esse programa simulou por vários dias/ano e a eficiência calculada do sistema foi de 13,86\% no inverno e 13,91\% no verão, sendo que os painéis foram ajustados manualmente e passaram a ter uma eficiência $20 \%$ maior.

É importante destacar que os sistemas fotovoltaicos de bombeamento de água podem ser aplicados em diversas áreas, sendo que as principais são: sistemas de irrigação, em pequenas comunidades, residenciais, destinadas ao consumo animal (CARVALHO, 2019).

\section{CONCLUSÕES}

O bombeamento de água por meio da utilização do sistema fotovoltaico é uma alternativa viável que leva a água de poços, represas, reservatórios, rios e lagos para serem utilizadas pelo homem nos mais variados ambientes, como residências, irrigações, consumo animal, pequenas comunidades, dentre outros.

O dimensionamento e escolha do motor e da bomba dependem um do outro, pois para cada aplicação existirá um conjunto motobomba que tenha um melhor desempenho de acordo com as condições de trabalho. Assim, é necessário conhecer os diferentes equipamentos disponíveis e entender que aplicação explora melhor suas características para optar sempre pela melhor opção em termos de eficiência e baixo custo.

Neste trabalho concluiu-se que as vantagens de utilização desse sistema, as mesmas pautam-se em: pouca manutenção; possui sistemas modulares que podem ser aumentados ou diminuídos, conforme a necessidade de bombeamento; não utiliza combustível fóssil; é um sistema silencioso e confiável; possui uma longa vida útil; não polui; é um sistema confiável; possui operação autônoma; tem baixo custo de operação e evita gastos permanentes (gastos com aquisição de combustíveis, por exemplo). Já as desvantagens, as mesmas pautam-se em: exige um alto investimento inicial; é uma tecnologia ainda pouco utilizada; depende do recurso solar.

\section{REFERÊNCIAS}

ALVARENGA, C. A.. Bombeamento de água com energia solar fotovoltaica. Engenharia Solenerg, 2019.

ALVARENGA, A. C.; FERREIRA, V. H.; FORTES, M. Z.. Energia solar fotovoltaica: uma aplicação na irrigação da agricultura familiar. Sinergia, São Paulo, v.15, n.4, p.311-318, 2014.

BALFOUR, J.; SHAW, M.; NASH, N. B.. Introdução ao projeto de sistemas fotovoltaicos. Rio de Janeiro: LTC, 2019.
BOITRAGO, S. A.; SANTOS, S. S.; GONÇALVES, A. H. R.; CANELA, M. A. R.. Captação de água por sistema fotovotaico para consumo humano na localidade rural Ilha Caiapós, São Romão, Minas Gerais. REEC - Revista Eletrônica de Engenharia Civil, v.12, n.2, 2016. DOI: http://doi.org/10.5216/reec.V12i2.37490

CARVALHO, C. E. B.. Bombeamento fotovoltaico de água para pequenas propriedades rurais do semiárido brasileiro: dimensionamento técnico e financeiro. Monografia 
(Bacharelado em Engenharia Elétrica) -Instituto Federal da Bahia, Paulo Afonso, 2019.

CARVALHO, R. D.. Aspectos econômicos e ambientais em sistema de abastecimento de água usando energia solar fotovoltaica e captação subterrânea. Dissertação (Mestrado em Engenharia Ambiental) -Universidade Federal de Santa Catarina, Florianópolis, 2016.

CARVALHO, R. D.; DALSASSO, R. L.; GUEDES, T. L.; SANTOS, J. A. C.. Otimização do dimensionamento em sistemas de bombeamento fotovoltaico: validação de modelo em sistema piloto na comunidade rural de Rio Belo, Orleans (SC). Eng. Sanit. Ambient., v.23, n.6, 2018. DOI: http://doi.org/10.1590/S1413-41522018160134

DAL BEM, J. C. T.; BARBI, I.; NORMEY-RICO, J. E.; RUTHER, R.. Solução para bombeamento de água em propriedades rurais utilizando energia solar fotovoltaica. Revista Brasileira de Energia Solar, v.7, n.7, p.50-57, 2016.

FERNANDES, R. O.. Estações elevatórias de água. Universidade Regional do Cariri, 2017.

JIMÉNEZ, J. P. V.. Projeto e dimensionamento de um sistema fotovoltaico isolado/conectado à rede para atender a demanda de irrigação de uva. Monografia (Bacharelado em Engenharia de Energia) - Universidade Federal da Integração Latino-Americana, Foz do Iguaçu, 2017.

MINAYO, M. C.. O desafio do conhecimento. São Paulo: Hucitec, 2010.
OLIVEIRA, E. N. C. S.; LIRA, M. A. T.; MORAES, A. M.. Sistemas fotovoltaicos de bombeamento de água na agricultura familiar piauiense. In: CONGRESSO BRASILEIRO DE ENERGIA SOLAR, 7. Anais. Gramado, 2018.

PINHO, J. T.; GALDINO, M. A.. Manual de engenharia para sistemas fotovoltaicos. Grupo de Trabalho de Energia Solar (GTES). CEPEL-DTE-CRESESB, 2014.

URBANETZ JUNIOR, J.; CASAGRANDE JUNIOR, E. F.; TIEPOLO, G. M.. Acompanhamento do desempenho do sistema fotovoltaico conectado à rede elétrica do escritório verde da UTFPR. In: CBPE, 9. Anais. Florianópolis, 2014.

VICENTIN, T. A.; SERAPHIM, O. J.; HALMEMAN, R. J.; PRESENÇO, J. F.; OLIVEIRA JÚNIOR, A. J.. Análise do acionamento de motobombas através de sistemas fotovoltaicos. Energ. Agric., Botucatu, v.31, n.1, p.72-79, 2016.

ZAGO, E. A.. Desempenho de um sistema de irrigação por gotejamento utilizando a energia fotovoltaica. Dissertação (Mestrado em Engenharia de Energia na Agricultura) Universidade Estadual do Oeste do Paraná, Cascavel, 2017.

ZILLI, B. M.. Sistema autônomo de bombeamento de água acionado por painéis fotovoltaicos amorfo e policristalino. Dissertação (Mestrado em Engenharia de Energia na Agricultura) - Universidade Estadual do Oeste do Paraná, Cascavel, 2018.

A CBPC - Companhia Brasileira de Produção Científica (CNPJ: 11.221.422/0001-03) detém os direitos materiais desta publicação. Os direitos referem-se à publicação do trabalho em qualquer parte do mundo, incluindo os direitos às renovações, expansões e disseminações da contribuição, bem como outros direitos subsidiários. Todos os trabalhos publicados eletronicamente poderão posteriormente ser publicados em coletâneas impressas sob coordenação da Sustenere Publishing, da Companhia Brasileira de Produção Científica e seus parceiros autorizados. Os (as) autores (as) preservam os direitos autorais, mas não têm permissão para a publicação da contribuição em outro meio, impresso ou digital, em português ou em tradução. 